\title{
Higher Socioeconomic Status is Associated with Improved Outcomes After Obesity Surgery Among Women in Germany
}

\author{
Jonas Wagner $^{1}{ }^{1} \cdot$ Nicola Zanker $^{1} \cdot$ Anna Duprée $^{1} \cdot$ Oliver Mann $^{1} \cdot$ Jakob Izbicki $^{1} \cdot$ Stefan Wolter $^{1}$
}

Accepted: 3 July 2021 / Published online: 26 July 2021

(C) The Author(s) 2021

\begin{abstract}
Background Low socioeconomic status (SES) is associated with an increased prevalence of obesity. It is unknown whether SES influences the outcome after bariatric surgery in Germany. Therefore, the aim of our study was to investigate whether the SES is linked with an inferior outcome after bariatric surgery.

Methods We included all patients who underwent bariatric surgery in our university hospital from 2012-2014. Net income was estimated by matching the zip codes of patient residency with the region-specific purchasing power index. We analyzed the relationship between SES, weight loss and remission of comorbidities.

Results We included 559 patients in this study and detected a mean 5-year percentage excess weight loss (\%EWL) of $52.3 \%$. We detected a significantly lower initial body mass index (BMI) and weight in patients with a higher income. One year after surgery, we did not find a significant difference. Further analysis revealed that only women with a higher income had a significantly lower BMI and weight 3 and 5 years after surgery.

Conclusions Bariatric surgery is beneficial for all patients regardless of income. Furthermore, we demonstrated that women with high SES have a better outcome after bariatric surgery.
\end{abstract}

\section{Introduction}

The prevalence of obesity has doubled worldwide in recent years, making obesity one of the most important global challenges [1]. This also applies to Germany [2]. Obesity increases the risk of chronic diseases, including cardiovascular disease, diabetes mellitus, kidney diseases [3], musculoskeletal diseases [4] and cancer [5].

Bariatric surgery is important as the most successful treatment option for obesity [6]. Successful bariatric surgery is viewed as \%EWL above 50\% [7]. All current procedures are associated with sustained long-term weight

Jonas Wagner

jowagner@uke.de

1 Department of General-, Visceral- and Thoracic Surgery, University Medical Center Hamburg-Eppendorf, Martinistrasse 52, 20246 Hamburg, Germany loss [8]. Some factors are known to influence weight loss following surgery. The procedure type seems to affect the expected \%EWL [8], while behavioral factors such as physical activity, dietary habits and health responsibilities do not affect the outcome [9].

Risk factors for developing obesity include the genetic predisposition, low physical activity, unhealthy eating behavior, sex and socioeconomic factors [10]. Socioeconomic factors are summarized as socioeconomic status, which is defined by the education, occupation and income of an individual or a group [11]. Obesity is distributed along a socioeconomic gradient, meaning that the prevalence of obesity is higher in people with low socioeconomic status [2]. Income alone influences the risk for obesity. This factor seems to be especially important for women [10].

A low SES is associated with a greater risk of chronic diseases and poorer outcome after therapy. Kucharska- 
Table 1 Patient characteristics

\begin{tabular}{|c|c|}
\hline$n$ & 559 \\
\hline Age [years] & $44.2 \pm 11.5$ \\
\hline Weight $[\mathrm{kg}]$ & $149.8 \pm 33.5$ \\
\hline Height $[\mathrm{cm}]$ & $172.2 \pm 9.6$ \\
\hline BMI $\left[\mathrm{kg} / \mathrm{m}^{2}\right]$ & $50.4 \pm 9.9$ \\
\hline Women $[\mathrm{n} / \%]$ & $388 / 69.4$ \\
\hline Men [n/\%] & $171 / 30.6$ \\
\hline \multicolumn{2}{|l|}{ Procedure: } \\
\hline Sleeve gastrectomy [n] & 270 \\
\hline Gastric bypass [n] & 260 \\
\hline Other $^{\mathrm{a}}[\mathrm{n}]$ & 29 \\
\hline Diabetes[n/\%] & $188 / 33.6$ \\
\hline Hypertension[n/\%] & $343 / 61.4$ \\
\hline OSAS[n/\%] & $75 / 13.4$ \\
\hline Hypertriglyceridemia[n/\%] & $241 / 43.1$ \\
\hline Hypercholesterolemia[n/\%] & $188 / 33.6$ \\
\hline Average income [€/year] & $24,128 \pm 3469$ \\
\hline Income $<€ 24,000 /$ year [n/\%] & $303 / 54.2$ \\
\hline
\end{tabular}

${ }^{a}$ Other procedures included gastric banding, single anastomosis duodeno-ileal bypass and conversion of sleeve gastrectomy to gastric bypass

Newton et al. showed that a low SES increases the risk of acute coronary heart disease events [12]. Additionally, Yong et al. reported that low SES leads to higher mortality after ST elevation myocardial infarction [13]. Regarding bariatric surgery, Carden et al. reported that in the USA, a lower SES is associated with reduced weight loss after bariatric surgery [14]. These aforementioned differences could partially be explained by accessibility of health care. In Germany, health insurance is mandatory, and healthcare access poses no problem [15]. Therefore, studying SES effects in Germany is a good choice, because the results should reflect true differences in SES, not in accessibility of health care.

However, the influence of SES on bariatric surgery in Germany has not been studied. It is relevant to explore whether SES, which influences the risk for obesity, also affects the outcome after bariatric surgery. Hence, we hypothesized that SES is in fact an influencing factor and is associated with an inferior outcome after bariatric surgery. Our study focused on the progression of weight, BMI, $\%$ TWL and \%EWL after bariatric surgery with regard to SES. As a secondary outcome, remission of other weightassociated medical conditions was detected.

\section{Materials and methods}

\section{Patient selection}

We conducted a retrospective analysis of our database of patients, who underwent bariatric surgery between 2012 and 2014. Perioperative and follow-up data were available for 559 patients. Certified bariatric surgeons in a German bariatric Center of Excellence performed all surgical procedures. All patients were screened before surgery by a multidisciplinary team consisting of an endocrinologist, psychologist, nutritionist, physical therapist and surgeon. Patients were selected for surgery with a BMI $>40 \mathrm{~kg} / \mathrm{m}^{2}$ or BMI $>35 \mathrm{~kg} / \mathrm{m}^{2}$ and related comorbidities in accordance with the German Guidelines of Surgical Treatment of Obesity after discussion at our interdisciplinary obesity board. The operating surgeon decided which procedure to perform depending on BMI, comorbidities, medication and patient request [16]. Data regarding demographics, initial height, weight, BMI, comorbidities, procedure, HbA1c and length of follow-up, as well as the follow-up data after 1,2, 3 and 5 years, including percent total weight loss (\%TWL) and percent excess weight loss (\%EWL), were collected. SES was indicated by net income per capita/month, which is an approved substitute marker. Income has previously been certified to correctly indicate SES [14, 17-20]. We used the purchasing power index (PPI) as a surrogate parameter to gain income information. The patient's zip code was matched with the according PPI of the specific region, as has been used before [14, 21]. The PPI data were purchased from Michael Bauer Research GmbH. We used $€ 2000$ per capita/month as a cutoff based on the GEDA study [22].

The primary outcome was the total weight, BMI, $\%$ TWL and \%EWL over time. Changes in other weightassociated medical conditions were examined as a secondary outcome. Patients under treatment regarding these conditions were defined as positive for weight-related diseases, according to the IDF consensus statement [23]. The American Society for Metabolic and bariatric Surgery criteria were used to define (partial) remission of weightrelated diseases [24].

The local ethics committee approved the clinical database. All patients gave informed consent.

\section{Statistics}

Statistical analysis was performed with the Statistical Package for Social Sciences software (SPSS; IBM, version 24). Patient characteristics are presented overall using the mean $\pm \mathrm{SD}$ for continuous variables. For comparisons between continuous variables, independent Student's t test 

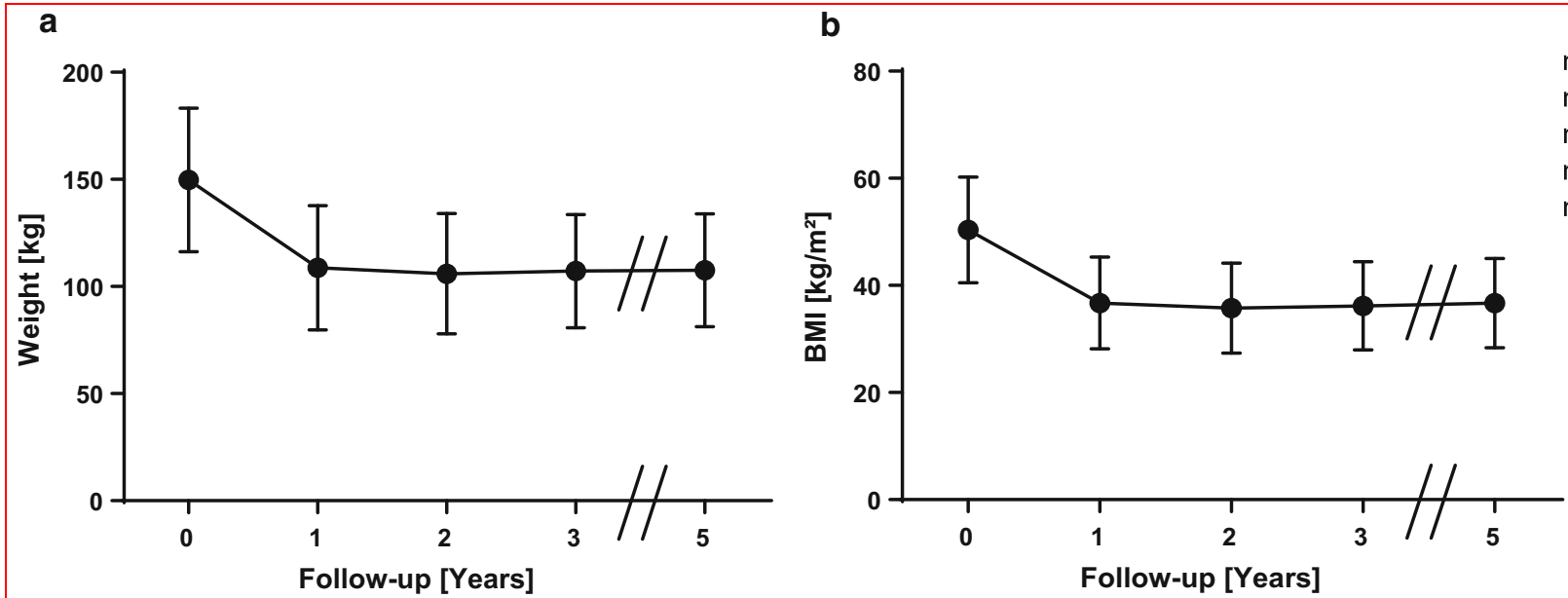

C

d
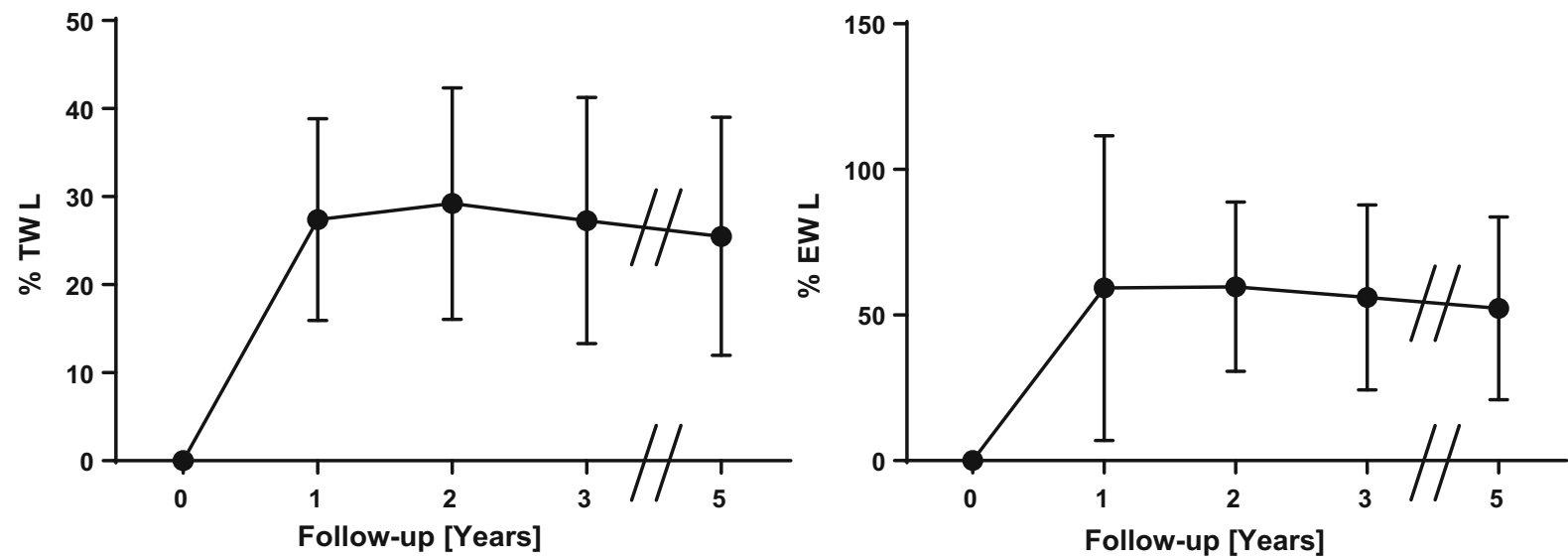

Fig. 1 Means and standard deviations of weight $\mathbf{a}, \mathrm{BMI} \mathbf{b}, \% \mathrm{TWL} \mathbf{c}$ and $\%$ EWL d of the general study population over 5 years. $n_{t}$ is the number of available and analyzed patients, while ${ }_{t}$ is the timepoint in years postoperatively

was performed. Linear regression was performed to validate income/head/year as an independent variable. Multiple linear regression was computed to predict weight and BMI with sex, age, procedure, income/head and comorbidities as independent variables. To determine differences between nominal data, a Chi-square test was used and, if numbers of events were smaller than 5, Fisher's exact test was performed. $p$-values $<0.05$ were considered to be statistically significant.

\section{Results}

\section{Patient's characteristics}

The characteristics of the patients are displayed in Table 1 . A total of 559 patients were included in this study. Followup data were available for $66.7 \%$ of patients after 1 year, for $68.3 \%$ after 2 years, for $59.9 \%$ after 3 years and for
$30.9 \%$ after 5 years. The initial mean weight was $149.8 \pm 33.5 \mathrm{~kg}$, with a BMI of $50.4 \pm 9.9 \mathrm{~kg} / \mathrm{m}^{2}$. The majority of the patients were female $(69.4 \%)$. The average income/per capita/year was $€ 24,128 \pm 3469$, while $54.2 \%$ had an estimated income of less than $€ 24,000$ annually. The most common comorbidity was hypertension (61.4\%), followed by diabetes (33.6\%) and OSA (13.4\%) (Table 1).

\section{Overall time course of weight, BMI, \% TWL and \%EWL}

We measured an average weight of $108.7 \pm 29 \mathrm{~kg}$ of the cohort after 1 year. After 2 years, the weight reached its nadir with $106 \pm 28 \mathrm{~kg}$, then went slightly up after 3 years and remained stable after 5 years (Fig. 1a). The initial BMI dropped to $36.8 \pm 8.5 \mathrm{~kg} / \mathrm{m}^{2}$ after 1 year, resulting in a change of $-13.6 \mathrm{~kg} / \mathrm{m}^{2}$. The nadir was reached after 2 years, and the mean slightly increased after 3 years and stabilized after 5 years (Fig. 1b). After 1 year, we detected 
Table 2 Patient characteristics in terms of socioeconomic status

\begin{tabular}{|c|c|c|c|}
\hline & Low SES (Income $\leq € 24,000 /$ year) & High SES (Income > $>24,000 /$ year) & $p$ value \\
\hline$n$ & 303 & 256 & \\
\hline Age [years] & $43.7 \pm 11.6$ & $44.9 \pm 11.4$ & 0.22 \\
\hline Weight $[\mathrm{kg}]$ & $152 \pm 35$ & $146 \pm 30$ & 0.023 \\
\hline Height $[\mathrm{cm}]$ & $172.3 \pm 9.6$ & $172.1 \pm 9.6$ & 0.84 \\
\hline BMI $\left[\mathrm{kg} / \mathrm{m}^{2}\right]$ & $51.3 \pm 10.3$ & $49.2 \pm 9.2$ & 0.016 \\
\hline Women $[\mathrm{n} / \%]$ & $209 / 69$ & $179 / 70$ & 0.8 \\
\hline $\operatorname{Men}[\mathrm{n} / \%]$ & $94 / 31$ & $77 / 30$ & 0.8 \\
\hline Procedure: & & & 0.17 \\
\hline Sleeve gastrectomy $[\mathrm{n}]$ & 159 & 111 & \\
\hline Gastric bypass [n] & 131 & 129 & \\
\hline Other $^{\mathrm{a}}[\mathrm{n}]$ & 13 & 16 & \\
\hline Diabetes[n/\%] & $109 / 36$ & $79 / 31$ & 0.2 \\
\hline Hypertension[n/\%] & $190 / 63$ & $151 / 59$ & 0.32 \\
\hline OSAS[n/\%] & $47 / 16$ & $28 / 11$ & 0.14 \\
\hline Hypertriglyceridemia[n/\%] & $123 / 41$ & $118 / 46$ & 0.12 \\
\hline Hypercholesterolemia[n/\%] & $105 / 35$ & $82 / 32$ & 0.64 \\
\hline Average income [€/year] & $21,804 \pm 1582$ & $26,881 \pm 3055$ & $<0.001$ \\
\hline
\end{tabular}

${ }^{\mathrm{a} O t h e r}$ procedures included gastric banding, single anastomosis duodeno-ileal bypass and conversion of sleeve gastrectomy to gastric bypass

a \%TWL of $27.4 \pm 11.5 \%$, which increased to $29.2 \pm 13.1 \%$ after 2 years. In the following years, we observed a slight drop (Fig. 1c). The progression of \% EWL was similar; after 1 year, it was $59.3 \pm 52.3 \%$, and then it reached its maximum 2 years postoperatively. It also dropped after 3 and 5 years postoperatively (Fig. 1d).

\section{Patients with higher income present themselves with lower weight and BMI}

We divided the cohort into a low SES $(n=303)$ and a high SES group $(n=254)$. The low SES group was defined as an estimated income lower than $€ 2000 /$ month/per capita [22]. We observed an initial significantly lower weight and BMI in the high SES group $(152.7 \pm 35.4 \mathrm{~kg}$ vs. $146.2 \pm 30.8 \mathrm{~kg}$ and $51.3 \pm 10.3 \mathrm{~kg} / \mathrm{m}^{2}$ vs. $\left.49.2 \pm 9.2 \mathrm{~kg} / \mathrm{m}^{2}\right) \quad(p<0.05)$. Additionally, the two groups only showed a significant difference in their average income $(p<0.05)$. Importantly, the groups were similar in procedure makeup (Table 2).

Over the course of the study period, the initial advantage vanished, although the high SES group had a significantly lower BMI after 3 years; after 5 years, no significant difference was detected (Fig. 2a, b). The course of the \% TWL and \%EWL showed no significant difference between the groups (Fig. 2c, d). We did not observe a difference in terms of remission of other weight-associated medical conditions (data not shown). We wondered whether we needed to reject our hypothesis that SES influences weight loss outcomes. Therefore, we performed linear regression analysis using income/head as an independent variable and BMI and weight as dependent variables. Although the proportion of explained variance was low, we observed that income was indeed an independent variable for BMI up to three years postoperatively and 1 year postoperatively for weight (Tables 3, 4).

\section{Women benefit from a higher income regarding total weight and BMI}

We were looking for an explanation of why income was an independent variable for weight loss, but we did not see an effect in our data. Among females in highly developed countries such as Germany, low income is associated with higher weight $[10,25,26]$. Therefore, we analyzed the data in terms of sex differences. We did not find any significant differences in men with high SES $(n=77)$ compared to men with lower SES $(n=94)$ (Fig. 3a-d). The female groups presented themselves with no significant difference in weight or BMI prior to operation. After 3 years, women with high SES $(n=179)$ established a significantly lower weight $(98 \pm 23.3 \mathrm{~kg}$ vs. $104.9 \pm 23.3 \mathrm{~kg}, p<0.05)$ and BMI $\left(34.5 \pm 7.8 \mathrm{~kg} / \mathrm{m}^{2}\right.$ vs. $\left.37 \pm 8.4 \mathrm{~kg} / \mathrm{m}^{2}, p<0.05\right)$ than females with low SES $(n=209)$. They also maintained a significant advantage in weight (97 $\pm 20.2 \mathrm{~kg}$ vs. $107 \pm 27.3 \mathrm{~kg})$ and BMI $\left(34.7 \pm 7.7 \mathrm{~kg} / \mathrm{m}^{2} \quad\right.$ vs. 


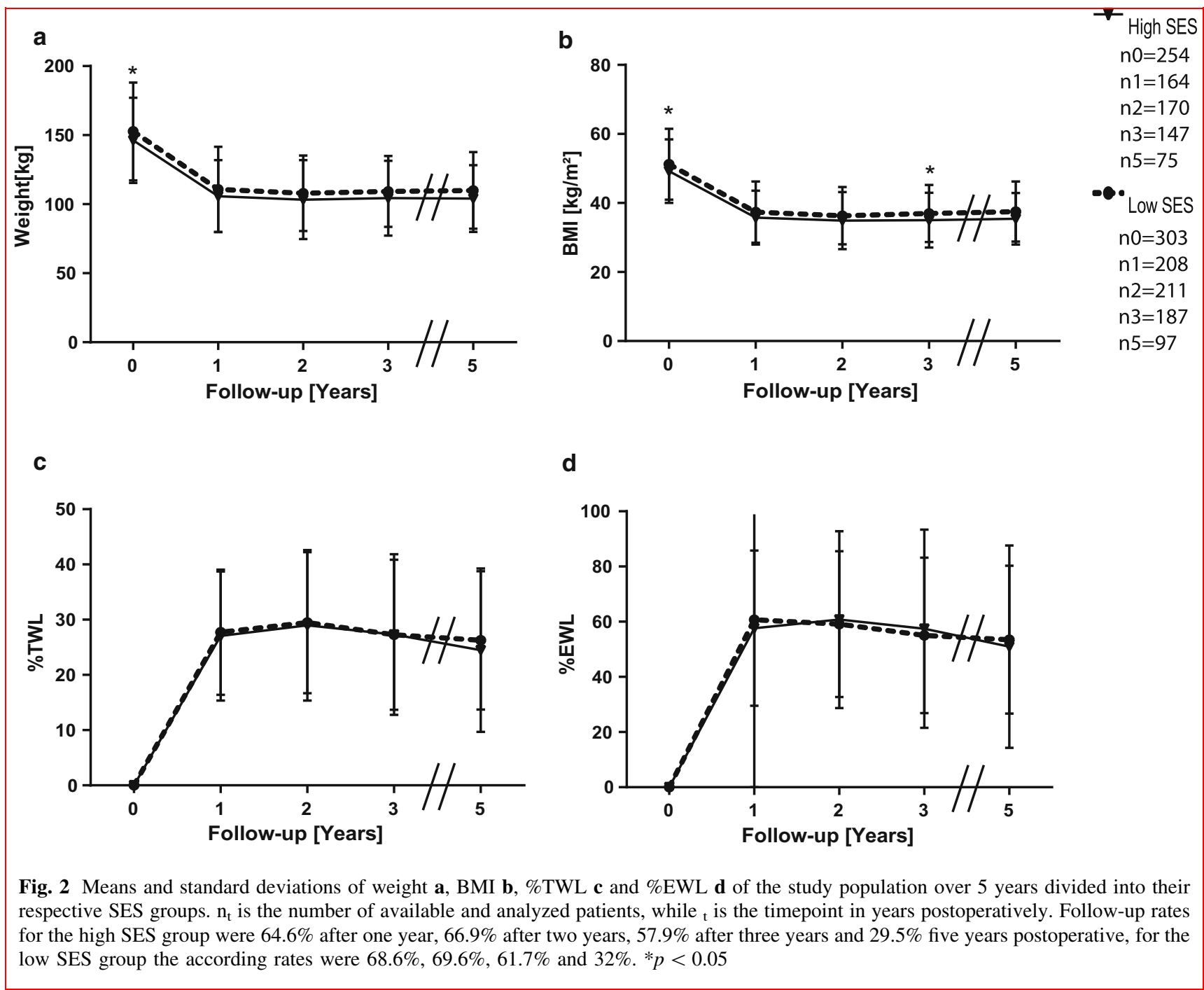

Table 3 Linear regression of income/head on BMI.

\begin{tabular}{lllll}
\hline BMI & 1 year postoperative & 2 years postoperative & 3 years postoperative & 5 years postoperative \\
\hline Overall & $0.024^{*}$ & $0.01^{*}$ & $0.013^{*}$ & 0.003 \\
Male & 0.025 & 0.001 & 0 & 0.012 \\
Female & $0.028^{*}$ & $0.02^{*}$ & $0.024^{*}$ & 0.005 \\
\hline
\end{tabular}

Coefficient of determination $\left(R^{2}\right)$ as numerical value and significance $(*)$

${ }^{*}$ denotes statistical significance $(p<0.05)$

$37.8 \pm 9.1 \mathrm{~kg} / \mathrm{m}^{2}$ ) 5 years postoperatively (Fig. $4 \mathrm{a}$, b). The procedure makeup of both female groups was similar (Table 5), indicating that the observed effect was caused by differences in SES. Furthermore, no difference in \%TWL, $\%$ EWL (Fig. 4c, d) or remission of other weight-associated medical conditions was observed (data not shown). We also performed linear regression and observed that income could only be regarded as an independent variable in females for BMI and weight up to three years postsurgery (Tables 3 and 4), further providing evidence that income affects only the weight loss of females postbariatric surgery. 
Table 4 Linear regression of income/head on weight.

\begin{tabular}{lllll}
\hline Weight & 1 year postoperative & 2 years postoperative & 3 years postoperative & 5 years postoperative \\
\hline Overall & $0.016^{*}$ & 0.005 & 0.01 & 0.006 \\
Male & 0.022 & 0 & 0 & 0.005 \\
Female & $0.023^{*}$ & $0.022^{*}$ & $0.024^{*}$ & 0.012 \\
\hline
\end{tabular}

Coefficient of determination $\left(R^{2}\right)$ as numerical value and significance $(*)$

* denotes statistical significance $(\mathrm{p}<0.05)$
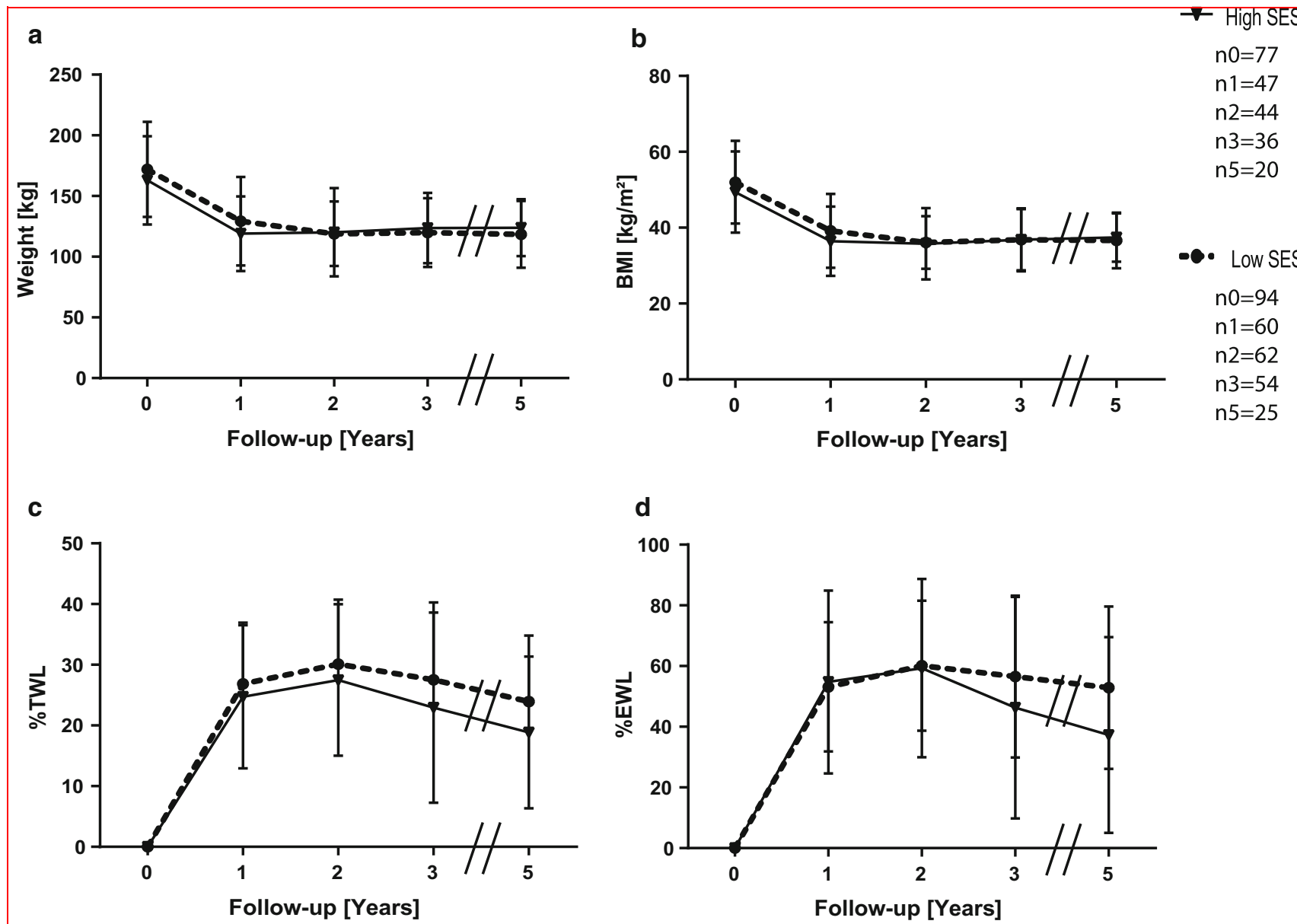

Fig. 3 Means and standard deviations of weight a, BMI b, \%TWL $\mathbf{c}$ and \%EWL d for men in different SES classes. $\mathrm{n}_{\mathrm{t}}$ is the number of available and analyzed patients for each group, while ${ }_{\mathrm{t}}$ is the timepoint in years postoperatively. Follow-up rates for men in the high SES group were $61 \%$ after one, $57.1 \%$ after two, $46.8 \%$ after three and $25.9 \%$ five years postoperative, for the low SES group the according rates were $63.8 \%, 66 \%$, $57.4 \%$ and $26.6 \%$

\section{Multiple linear regression analysis}

Additionally, we performed multiple linear regression to see how income would perform compared to other variables. We used the type of procedure, income/head, comorbidities (diabetes, OSA, hypertension, dyslipidemia), sex and age as independent variables. This model showed a significant influence of the procedure type, income/head and diabetes on BMI one year after surgery. After two and three years, only the procedure was predictive. After 5 years, the procedure and OSA were predictive. We used the same variables to predict weight and observed a similar picture. One year after surgery, the type of procedure, income/head, sex and age significantly influenced the weight. After two and three years, only procedure and sex were predictive. After 5 years, we discovered the type of 

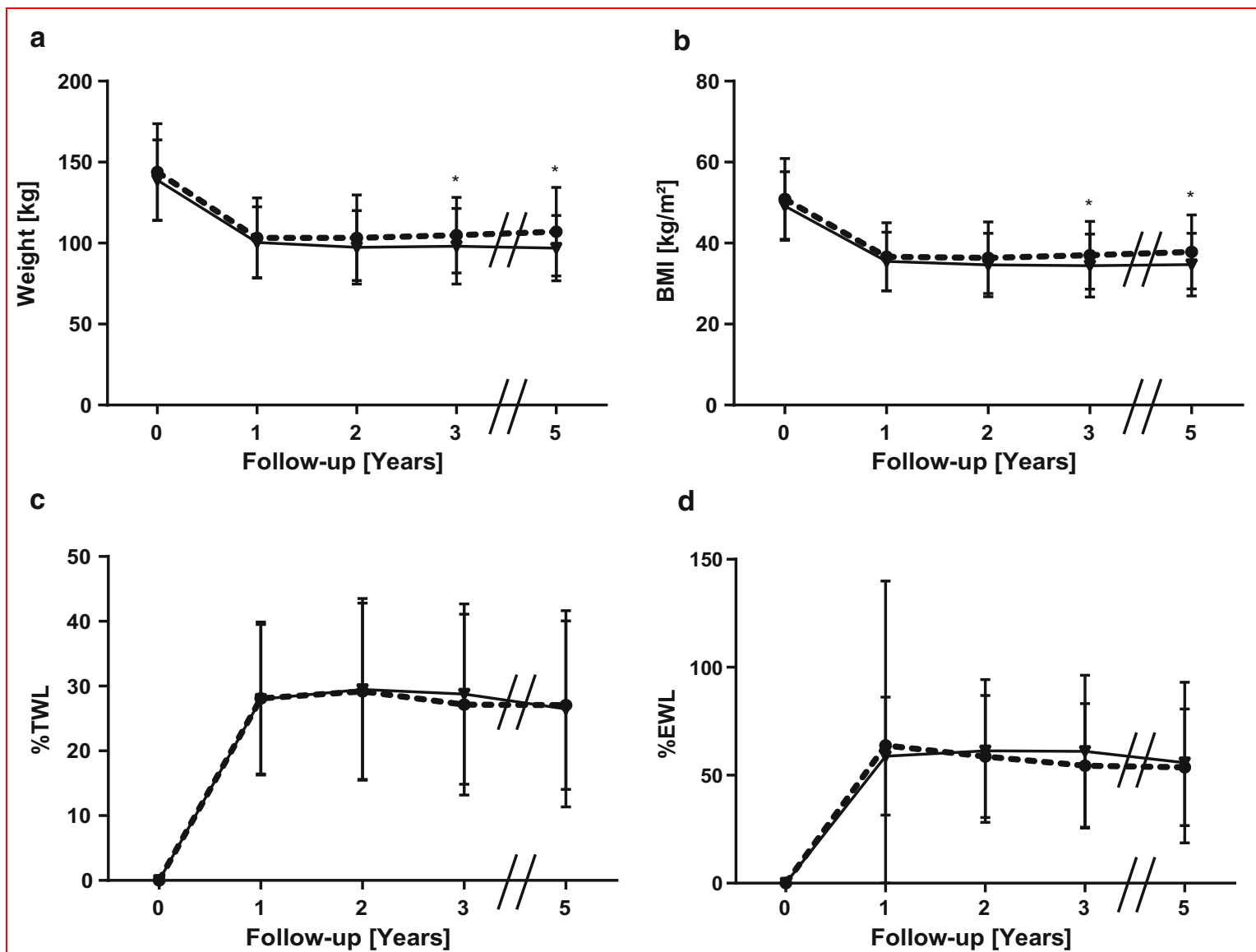

High SES
$n 0=179$
$n 1=117$
$n 2=126$
$n 3=111$
$n 5=55$
Low SES
$n 0=209$
$n 1=148$
$n 2=149$
$n 3=133$
$n 5=72$

d

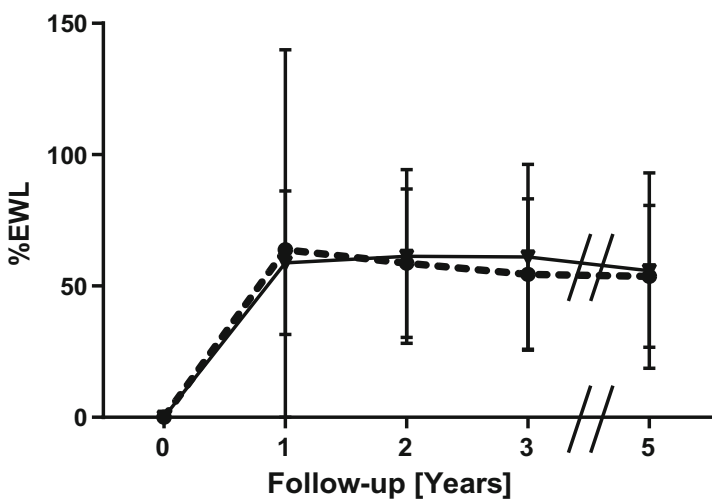

Fig. 4 Means and standard deviations of weight $\mathbf{a}$, BMI b, \% TWL $\mathbf{c}$ and \%EWL d for women in different SES classes. $\mathrm{n}_{\mathrm{t}}$ is the number of available and analyzed patients for each group, while ${ }_{t}$ is the timepoint in years postoperatively. Follow-up rates for women in the high SES group were $65.3 \%$ after one, $70.3 \%$ after two, $62 \%$ after three and $30.7 \%$ five years postoperative, for the low SES group the according rates were $70.8 \%, 71.3 \%, 63.6 \%$ and $34.4 \%$. ${ }^{*} p<0.05$

procedure, sex, OSA and dyslipidemia as influencing factors. We wondered whether these models would again perform better for female patients. The model for the female cohort showed a similar picture as the total cohort. The model could not predict BMI or weight for the male cohort (Tables 6, 7). This justified our sex-specific considerations further.

\section{Type of procedure}

However, the cohorts were homogenous regarding their type of procedures. We still wondered whether there was a procedure-specific effect. We compared the patients undergoing sleeve gastrectomy and patients undergoing gastric bypass surgery. Patients who received gastric bypass surgery had significantly $(p<0.05)$ lower BMI and weight (Fig. 5). Then, we split the cohorts based on income and procedure type. We observed significantly lower weight after 5 years in the high SES bypass group (Fig. 6a) but no difference in BMI (Fig. 6b). The sleeve groups only initially showed a significant difference $(p<0.05)$ in weight and BMI (Fig. 6c, d).

\section{Discussion}

In this study, we assessed whether socioeconomic status impacts the outcome after bariatric surgery in Germany. First, we detected a good outcome after bariatric surgery, indicated by a \%EWL above 50 through 5 years postoperatively, regardless of the SES. We observed that people with high SES present themselves with lower weight and BMI compared to patients with low SES. This difference could not be detected after 5 years. We used linear regression to show that income was indeed an independent variable for weight loss outcomes. In females, an inverse correlation exists between income and weight $[10,25,26]$. Therefore, we evaluated whether a sex-specific effect might be present. We observed that females with high SES had a lower weight and BMI up to 5 years postoperatively. 
Table 5 Female patient characteristics

\begin{tabular}{lllr}
\hline & Low SES (Income $\leq € 24,000 /$ year) & High SES (Income $>€ 24,000 /$ year) & $p$ value \\
\hline $\mathrm{n}$ & 209 & 179 & 0.32 \\
Age [years] & $42.4 \pm 10.7$ & $43.5 \pm 11.2$ & 0.09 \\
Weight [kg] & $144 \pm 29$ & $139 \pm 25$ & 0.74 \\
Height [cm] & $168.1 \pm 6.7$ & $167.8 \pm 6.8$ & 0.1 \\
BMI [kg/m ${ }^{2}$ ] & $50.9 \pm 10$ & $49.3 \pm 8.6$ & \\
Procedure: & & 65 & 0.17 \\
Sleeve gastrectomy [n] & 95 & 107 & 7 \\
Gastric bypass [n] & 105 & $52 / 30$ \\
Other ${ }^{2}[\mathrm{n}]$ & 9 & $96 / 54$ \\
Diabetes[n/\%] & $71 / 35$ & $21 / 13$ \\
Hypertension[n/\%] & $125 / 60$ & $71 / 43$ \\
OSAS[n/\%] & $24 / 14$ & $61 / 37.2$ & 0.32 \\
Hypertriglyceridemia[n/\%] & $74 / 38$ & $26,656 \pm 2631$ \\
Hypercholesterolemia[n/\%] & $77 / 39.5$ & 0.2 \\
Average income [€/year] & $21,830 \pm 1526$ & 0.91 \\
\hline
\end{tabular}

${ }^{\text {a } O t h e r ~ p r o c e d u r e s ~ i n c l u d e d ~ g a s t r i c ~ b a n d i n g, ~ s i n g l e ~ a n a s t o m o s i s ~ d u o d e n o-i l e a l ~ b y p a s s ~ a n d ~ c o n v e r s i o n ~ o f ~ s l e e v e ~ g a s t r e c t o m y ~ t o ~ g a s t r i c ~ b y p a s s ~}$

Table 6 Multiple linear regression for BMI. Adjusted coefficient of determination $\left(\mathrm{R}^{2}\right)$ as numerical value, significance $(*)$ and independent variables

\begin{tabular}{lllll}
\hline Weight & 1 year postoperative & 2 years postoperative & 3 years postoperative & 5 years postoperative \\
\hline Overall & $0.126^{* 1,2,3}$ & $0.12 *^{1}$ & $0.10 *^{1}$ & $0.123 * 1,6$ \\
Male & $\mathrm{NS}$ & $0.306^{* 1,9}$ & $\mathrm{NS}$ & $0.366^{*}(\mathrm{constant)}$ \\
Female & $0.14 *^{* 1,2}$ & $0.11 *^{* 1}$ & $0.158^{* 1,6}$ & $0.149 * 6,9$ \\
\hline
\end{tabular}

* denotes statistical significance $(\mathrm{p}<0.05), \mathrm{NS}=$ not significant

Numbers denote significant variables $(1=$ procedure, $2=$ income/head, $3=$ diabetes, $4=$ hypercholesterolemia, $5=$ hyperglyceridemia, $6=$ OSA, $7=$ hypertension, $8=\operatorname{sex}, 9=$ age)

Table 7 Multiple linear regression for weight. Adjusted coefficient of determination $\left(\mathrm{R}^{2}\right)$ as numerical value, significance $(*)$ and independent variables

\begin{tabular}{lllll}
\hline Weight & 1 year postoperative & 2 years postoperative & 3 years postoperative & 5 years postoperative \\
\hline Overall & $0.23 *^{1,2,8,9}$ & $0.244^{1,8}$ & $0.21 *^{1,8}$ & $0.29 * 1,5,6,8$ \\
Male & $\mathrm{NS}$ & $0.284^{1,5}$ & $\mathrm{NS}$ & $\mathrm{NS}$ \\
Female & $0.18 *^{1,2}$ & $0.136^{* 1,2}$ & $0.169 * 1$ & $0.149 * 1,6$ \\
\hline
\end{tabular}

* denotes statistical significance $(p<0.05)$, NS $=$ not significant

Numbers denote significant variables $(1=$ procedure, $2=$ income/head, $3=$ diabetes, $4=$ hypercholesterolemia, $5=$ hyperglyceridemia, $6=$ OSA, $7=$ hypertension, $8=$ sex, $9=$ age)

Previous studies that analyzed the impact of SES came to various conclusions. In 2008, Akkary et al. could not detect an advantage for patients with high SES [27]. More recently, Carden et al. reported that in a Veteran population, which consisted of mostly males, low SES led to significantly lower weight loss [14]. Our data suggest that only females with high SES have a better outcome. A study from Andersen et al. showed that predictors of weight loss following sleeve gastrectomy are sex-specific. Unemployment in women resulted in lower percent excess body mass 

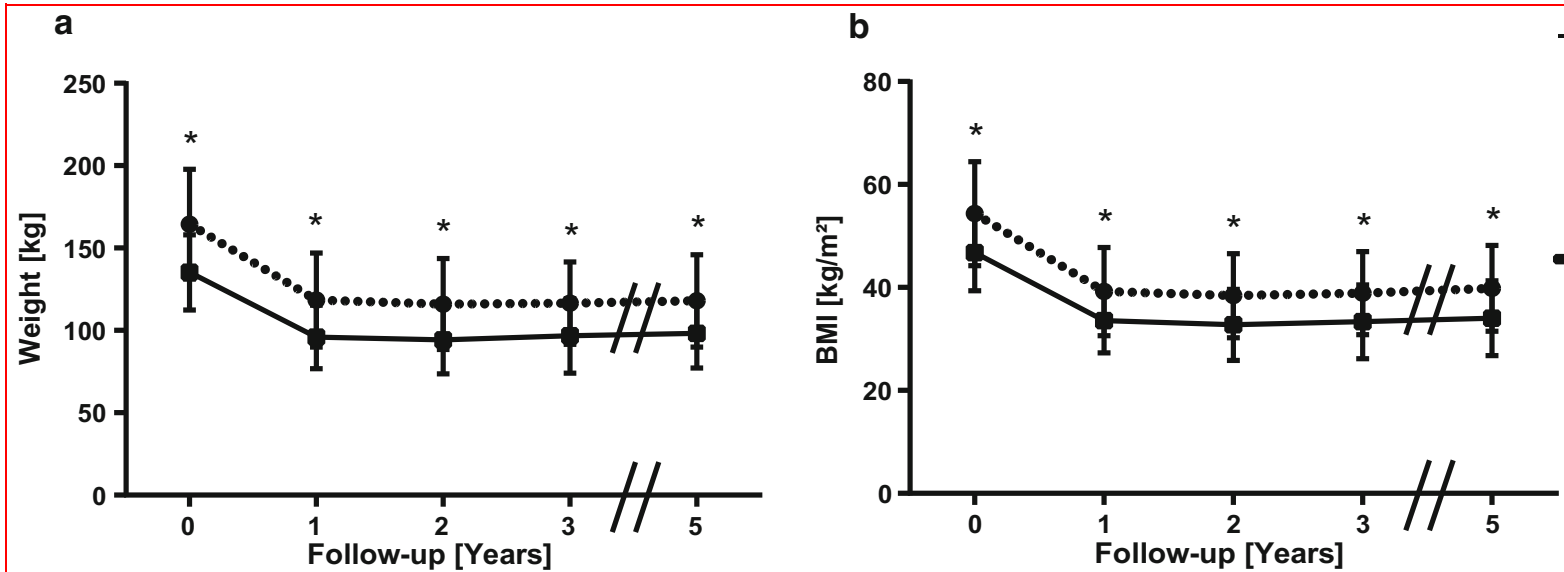

- RYGB

n0 $=260$

$\mathrm{n} 1=163$

$\mathrm{n} 2=178$

n3 $=153$

n5 $=89$

- Sleeve

n0 $=270$

$\mathrm{n} 1=191$

$\mathrm{n} 2=189$

n3 $=166$

n5 $=77$

Fig. 5 Means and standard deviations of weight $\mathbf{a}$, BMI $\mathbf{b}$ for patients undergoing sleeve or bypass surgery. $n_{t}$ is the number of available and analyzed patients for each group, while ${ }_{t}$ is the timepoint in years postoperatively. ${ }^{*} p<0.05$

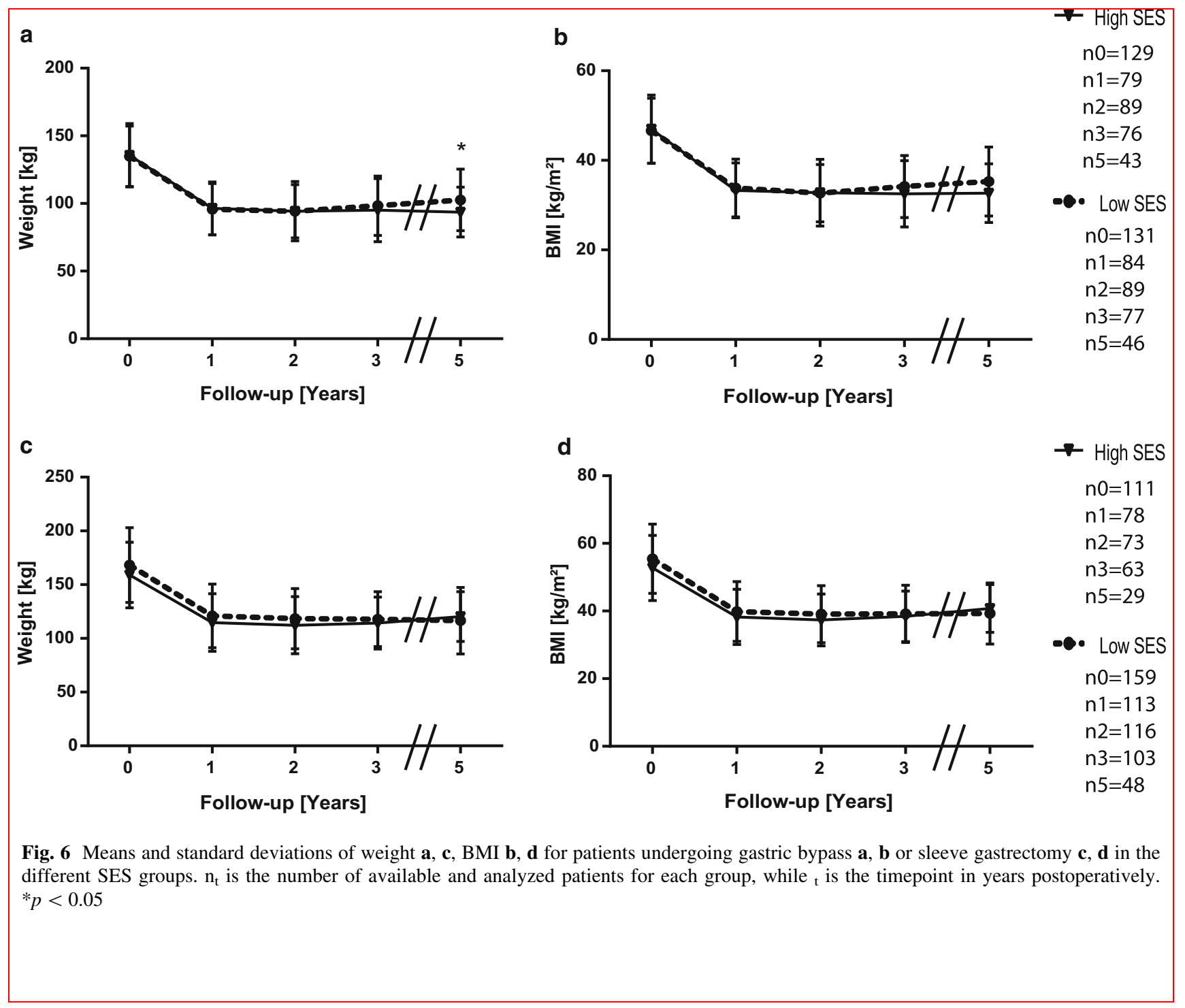


index loss (\%EBMIL) [28]. Which socioeconomic factors exactly influence the postoperative outcome remains to be examined. Women of lower-income classes have an increased risk for developing obesity [10]. Lower-income households seem to have less access to healthy food [29], and many women are still solely responsible for food purchase and preparation [25]. Access to physical activity or confidence to pursue physical activity can be reduced in women of low-income households [30]. Whether these factors also contribute to inferior weight loss in women with low SES after bariatric surgery remains to be determined. Further studies are needed to elucidate the exact socioeconomic aspects that contribute to a better outcome.

We observed that patients with high SES presented themselves with lower weight and BMI. Five years after surgery, this advantage disappeared. This indicates that bariatric surgery is distinguished regardless of SES. We detected no difference in \% TWL and \%EWL between the SES groups. The \%TWL and \%EWL are not the only markers for success after bariatric surgery and are not undisputed [31]. Individual patients are most likely only concerned about their total weight and BMI, since BMI is correlated with higher mortality [32]. This is the reason we focused on the total BMI and not the \% TWL or \%EWL.

This retrospective study suffers from some limitations. We used an approximation for the patient's income, meaning that it is possible that patients were assigned to the wrong group. Additionally, the relocation of a patient could not be detected. However, this is an established tool $[14,21]$. The strength of this study is the large sample size, which can reduce the errors of this tool. Another limitation is the low follow-up rate after 5 years $(30.9 \%)$. Loss to follow-up is a problem after bariatric surgery, and attrition rates increase year by year [33]. However, through our large sample size, we still analyzed 174 patients and therefore concluded that our findings are valid.

Our results show that bariatric surgery is effective for all socioeconomic classes. Low income is a risk factor in women for an inferior outcome after bariatric surgery. Further studies should focus on elucidating the exact factors that induce these effects to aid all patients.

\section{Conflict of interest}

The authors declare that they have no conflict of interest.

\section{Ethical approval}

This study was approved by the local ethics committee.

\section{Informed consent}

Informed consent was obtained from all individual participants included in the study.

Open Access This article is licensed under a Creative Commons Attribution 4.0 International License, which permits use, sharing, adaptation, distribution and reproduction in any medium or format, as long as you give appropriate credit to the original author(s) and the source, provide a link to the Creative Commons licence, and indicate if changes were made. The images or other third party material in this article are included in the article's Creative Commons licence, unless indicated otherwise in a credit line to the material. If material is not included in the article's Creative Commons licence and your intended use is not permitted by statutory regulation or exceeds the permitted use, you will need to obtain permission directly from the copyright holder. To view a copy of this licence, visit http://creativecommons. org/licenses/by/4.0/.

Funding Open Access funding enabled and organized by Projekt DEAL.

\section{References}

1. Collaborators GO (2017) Health effects of overweight and obesity in 195 countries over 25 years. $N$ Engl J Med 377(371):313-327

2. Hoebel J, Kuntz B, Kroll LE, Schienkiewitz A, Finger JD, Lange C, Lampert T (2019) Socioeconomic inequalities in the rise of adult obesity: a time-trend analysis of national examination data from Germany, 1990-2011. Obes Facts 12(3):344-56

3. Singh GM, Danaei G, Farzadfar F et al (2013) The age-specific quantitative effects of metabolic risk factors on cardiovascular diseases and diabetes: a pooled analysis. PLoS One 8:e65174

4. Jiang LTW, Wang Y, Rong J, Bao C, Liu Y, Zhao Y, Wang C (2012) Body Mass index and susceptibility to knee osteoarthritis: a systematic review and meta-analysis. Joint Bone Spine 79(3):291-297

5. Lauby-Secretan B, Scoccianti C, Loomis D, Grosse Y, Bianchini F, Straif K (2016) Body fatness and cancer-viewpoint of the IARC working group. New Engl J Med 357(8):741-752

6. Sjöström L, Narbro K, Sjöström D, Karason K, Larsson B, Wedel H, Lystig T, Sullivan M, Bouchard C, Carlsson B, Bengtsson C, Dahlgren S, Gummesson A, Jacobson P, Karlsson J, Lindroos AK, Lönroth H, Näslund I, Olbers T, Stenlöf K, Torgerson J, Ågren G, Carlsson LMS (2007) Effects of bariatric surgery on mortality in swedish obese subjects. New Engl J Med 357(8):741-752

7. Mann JP, Jakes AD, Hayden JD, Barth JH (2015) Systematic review of definitions of failure in revisional bariatric surgery. Obes Surg 25(3):571-574

8. O'Brien PHA, Brennan L, Skinner S, Burton P, Smith A, Crosthwaite G, Brown W (2019) Long-term outcomes after bariatric surgery: a systematic review and meta-analysis of weight loss at 10 or more years for all bariatric procedures and a single-centre review of 20-year outcomes after adjustable gastric banding. Obes Surg 29(1):3-14

9. Ryder JR, Gross AC, Fox CK, Kaizer AM, Rudser KD, Jenkins TM, Ratcliff MB, Kelly AS, Kirk S, Siegel RM, Inge TH (2018) Factors associated with long-term weight-loss maintenance following bariatric surgery in adolescents with severe obesity. Int J Obes 42(1):102-107 
10. Kuntz B, Lampert T (2010) Socioeconomic factors and obesity. Deutsches Ärzteblatt Int. https://doi.org/10.3238/arztebl.2010. 0517

11. Nakamura T, Nakamura Y, Saitoh S, Okamura T, Yanagita M, Yoshita K, Kita Y, Murakami Y, Yokomichi H, Nishi N, Okuda N, Kadato A, Ohkubo T, Ueshima H, Okayama A, Miura K (2018) Relationship between socioeconomic status and the prevalence of underweight, overweight or obesity in a general Japanese population: NIPPON DATA2010. J Epidemiol. https:// doi.org/10.2188/jea.JE20170249

12. Kucharska-Newton AM, Harald K, Rosamond WD et al (2011) Socioeconomic indicators and the risk of acute coronary heart disease events: comparison of population-based data from the United States and Finland. Ann Epidemiol 21:572-579

13. Yong CM, Abnousi F, Asch SM et al (2014) Socioeconomic inequalities in quality of care and outcomes among patients with acute coronary syndrome in the modern era of drug eluting stents. J Am Heart Assoc 3:e01029

14. Carden A, Blum K, Arbaugh CJ et al (2019) Low socioeconomic status is associated with lower weight-loss outcomes 10-years after Roux-en-Y gastric bypass. Surg Endosc 33:454-459

15. Busse R, Blumel M (2014) Germany: Health system review. Health Syst Transit 16(1-296):xxi

16. Dietrich A, Aberle J, Wirth A et al (2018) Obesity surgery and the treatment of metabolic diseases. Dtsch Arztebl Int 115:705-711

17. van den Berg I, Buettner S, van den Braak R et al (2020) Low socioeconomic status is associated with worse outcomes after curative surgery for colorectal cancer: results from a large, multicenter study. J Gastrointest Surg 24:2628-2636

18. Lantz PM, House JS, Lepkowski JM et al (1998) Socioeconomic factors, health behaviors, and mortality: results from a nationally representative prospective study of US adults. JAMA 279:1703-1708

19. Sabanayagam C, Shankar A (2012) Income is a stronger predictor of mortality than education in a national sample of US adults. J Health Popul Nutr 30:82

20. Geyer S, Peter R (2000) Income, occupational position, qualification and health inequalities-competing risks?(Comparing indicators of social status). J Epidemiol Community Health 54:299-305

21. Roswall J, Almqvist-Tangen G, Holmén A, Alm B, Bergman S, Dahlgren J, Strömberg U (2016) Overweight at four years of age in a Swedish birth cohort: influence of neighbourhood-level purchasing power. BMC Public health. https://doi.org/10.1186/ s12889-016-3252-1

22. Lampert TKL, Müters S, Stolzenberg H (2013) Measurement of the socioeconomic status within the German Health Update 2009 (GEDA)Bundesgesundheitsblatt. Gesundh Gesundh 56(51):131-143

23. Alberti KG, Zimmet P, Shaw J (2006) Metabolic syndrome-a new world-wide definition. A consensus statement from the international diabetes Federation. Diabet Med J British Diabet Assoc 23:469-480

24. Brethauer SA, Kim J, el Chaar M et al (2015) Standardized outcomes reporting in metabolic and bariatric surgery. Surg Obes Relat Dis 11:489-506
25. McLaren L (2007) Socioeconomic status and obesity. Epidemiol Rev 29(1):29-48

26. Pavela G, Lewis DW, Locher J, Allison DB (2016) Socioeconomic status, risk of obesity, and the importance of Albert J. Stunkard Current. Obes Rep 5(1):132-139

27. Akkary E, Nerlinger A, Yu S et al (2009) Socioeconomic predictors of weight loss after laparoscopic Roux-Y gastric bypass. Surg Endosc 23:1246-1251

28. Andersen JR, Aadland E, Nilsen RM et al (2014) Predictors of weight loss are different in men and women after sleeve gastrectomy. Obes Surg 24:594-598

29. Lovasi GS, Hutson MA, Guerra M, Neckerman KM (2009) Built environments and obesity in disadvantaged populations. Epidemiol Rev 31(1):7-20

30. Bennet GG, McNeill LH, Wolin KY, Duncan DT, Puleo E, Emmons KM (2007) Safe to walk? Neighborhood safety and physical activity among public housing residents. PLoS Medicine 4(10):e306

31. van de Laar A, de Caluwe L, Dillemans B (2011) Relative outcome measures for bariatric surgery. Evidence against excess weight loss and excess body mass index loss from a series of laparoscopic Roux-en-Y gastric bypass patients. Obes Surg 21:763-767

32. Prospective Studies C, Whitlock G, Lewington S et al (2009) Body-mass index and cause-specific mortality in 900000 adults: collaborative analyses of 57 prospective studies. Lancet 373:1083-1096

33. O'Brien PE, Hindle A, Brennan L et al (2019) Long-term outcomes after bariatric surgery: a systematic review and metaanalysis of weight loss at 10 or more years for all bariatric procedures and a single-centre review of 20-year outcomes after adjustable gastric banding. Obes Surg 29:3-14

Publisher's Note Springer Nature remains neutral with regard to jurisdictional claims in published maps and institutional affiliations.

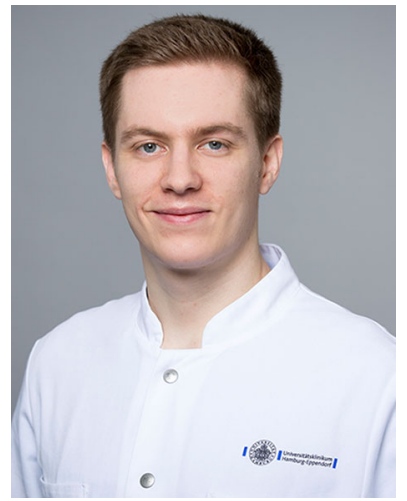

Jonas Wagner was raised in Germany and studied medicine at the RWTH Aachen University. Afterward, he moved to Hamburg and started his residency at the Department of General, Visceral and Thoracic Surgery at the University Medical Center Hamburg-Eppendorf. His main clinical interest and research is in bariatric surgery. $\mathrm{He}$ is interested in improving the outcome of bariatric surgery as well as developing new diagnostics and therapies for obesity-related comorbidities. In his free time he tries to catch some waves at various beaches in Europe. 